\title{
Análise fisiográfica da Estação Ecológica Serra Geral do Tocantis - Estados do Tocantins e Bahia
}

\author{
Sandro Sidnei Vargas de Cristo ${ }^{(\mathrm{a})}$ Luis Eduardo de Souza Robaina ${ }^{(\mathrm{b})}$ Romário Trentin $^{(\mathrm{c})}$ \\ (a)Pós-doutorando em Geografia / Programa de Pós-Graduação em Geografia / Departamento de Geociências / \\ Universidade Federal de Santa Maria; Professor do Curso de Geografia (Campus de Porto Nacional) da \\ Universidade Federal do Tocantins; Email sidneicristo@uft.edu.br

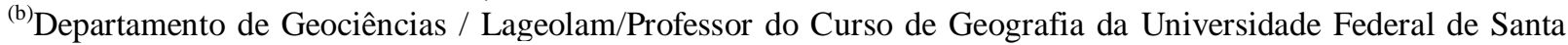 \\ Maria, Email lesrobaina@yahoo.com.br \\ ${ }^{(c)}$ Departamento de Geociências / Lageolam/Professor do Curso de Geografia da Universidade Federal de Santa \\ Maria, Email romario.trentin@gmail.com
}

\section{EIXO: BIOGEOGRAFIA, MANEJO DE ÁREAS NATURAIS E PROTEGIDAS: CONSERVAÇÃO DA BIODIVERSIDADE}

\begin{abstract}
Resumo:
O trabalho consiste na análise fisiográfica da Estação Ecológica Serra Geral do Tocantins, localizada entre o Tocantins e a Bahia, objetivando relacionar os aspectos geomorfológicos e hidrográficos com a conservação ambiental da área. Na metodologia utilizou-se o geoprocessamento e a organização de um banco de dados via SIG com o software SPRING do INPE. Destaca-se o uso de cartas topográficas, imagens de satélite (Landsat) e radar (SRTM/Topodata), mapas, arquivos digitais, e diversos trabalhos de campo. Na geomorfologia caracterizou-se as planícies de inundação, as dunas eólicas, os vales abertos e fechados, as colinas arenosas, os morros e morrotes, as mesas e mesetas, e as chapadas. Na hidrografia foram analisados parâmetros morfométricos como hierarquia fluvial, direção da rede de drenagem, magnitude e comprimento total, densidade e padrões de drenagem. Os resultados demonstraram a importância da geomorfologia e da hidrografia na conservação ambiental da área e do Cerrado em geral.
\end{abstract}

Palavras chave: Análise Fisiográfica; Unidades de Conservação da Natureza; Geomorfologia; Hidrografia; Conservação Ambiental

\section{Introdução}

O estudo das Unidades de Conservação da Natureza, vem demonstrando, cada vez mais, sua importância na conservação ambiental dos diferentes biomas brasileiros, sua fauna e flora, resultando em um aumento do interesse na realização de pesquisas com esta temática.

Da mesma forma, os estudos com abordagens geográficas, incluindo-se os aspectos hidrográficos e geomorfológicos de uma Unidade de Conservação da Natureza, tem demonstrado que estes aspectos tornam-se elementos primordiais na manutenção da biota e na definição de processos responsáveis pela esculturação e formatação da sua paisagem. 
Assim, os estudos relacionados a caracterização fisiográfica com ênfase as características da rede de drenagem e da geomorfologia, foram desenvolvidos na Estação Ecológica Serra Geral do Tocantins. Esta representa uma importante parcela do Bioma Cerrado, o qual abriga segundo Myers et al, 2000, as últimas grandes extensões da única área de savana considerada como um hotspot global de biodiversidade.

Com base em Myers et al (2000) hotspot é toda área prioritária para conservação, isto é uma área de conservação da biodiversidade e que está ameaçada no mais alto grau.

Neste contexto pode-se destacar que a Estação Ecológica Serra Geral do Tocantins, objeto de estudo, é uma Unidade de Conservação da Natureza integrante do Sistema Nacional de Unidades de Conservação - SNUC (Lei $n^{\circ} .9 .985$ de 18/07/2000) criado pela Lei $n^{\circ} .42 .009$ de 12 de dezembro de 2002.

Segundo Guerra e Marçal (2006) as unidades de conservação podem ser beneficiadas pelos conhecimentos geomorfológicos para os trabalhos de Zoneamento Ambiental e, em especial, a execução de Planos de Manejo. Além disso, podem ser utilizadas para recuperação de áreas degradadas, desenvolvimento de técnicas adequadas ao desenvolvimento do turismo ecológico e a definição de trilhas e áreas a serem melhores aproveitadas.

De acordo com Milani e Canali (2000) a aplicação da análise morfométrica facilita a compreensão de forma integrada dos processos hidrogeomorfológicos que ocorrem numa bacia hidrográfica, mesmo quando a sua estruturação é complexa, pois, a partir de uma análise global, pode-se setorizar os seus elementos e identificar à participação isolada de cada um. Isto pode ser aplicado em estudos de unidades de conservação, como é o caso da presente pesquisa.

A Estação Ecológica Serra Geral do Tocantins foi criada pelo Decreto Federal de 27 de setembro de 2001, com objetivo de proteger e preservar amostras dos ecossistemas de Cerrado, bem como propiciar o desenvolvimento de pesquisas científicas.

Neste trabalho, busca-se realizar uma análise fisiográfica da Estação Ecológica em questão, destacando-se os aspectos hidrográficos e geomorfológicos como elementos fundamentais na caracterização e conservação ambiental desta paisagem.

A área está localizada na região do Jalapão, ficando em grande parte no sudeste do Estado do Tocantins (municípios de Mateiros, Ponte Alta do Tocantins, Almas e Rio da Conceição) com uma pequena parte no extremo oeste do Estado da Bahia (município de Formosa do Rio Preto). Abrange uma área de aproximadamente 707.144ha, sendo que cerca de 631.598ha ficam no Estado do Tocantins e de 75.545ha ficam no Estado da Bahia. (Figura 1) 


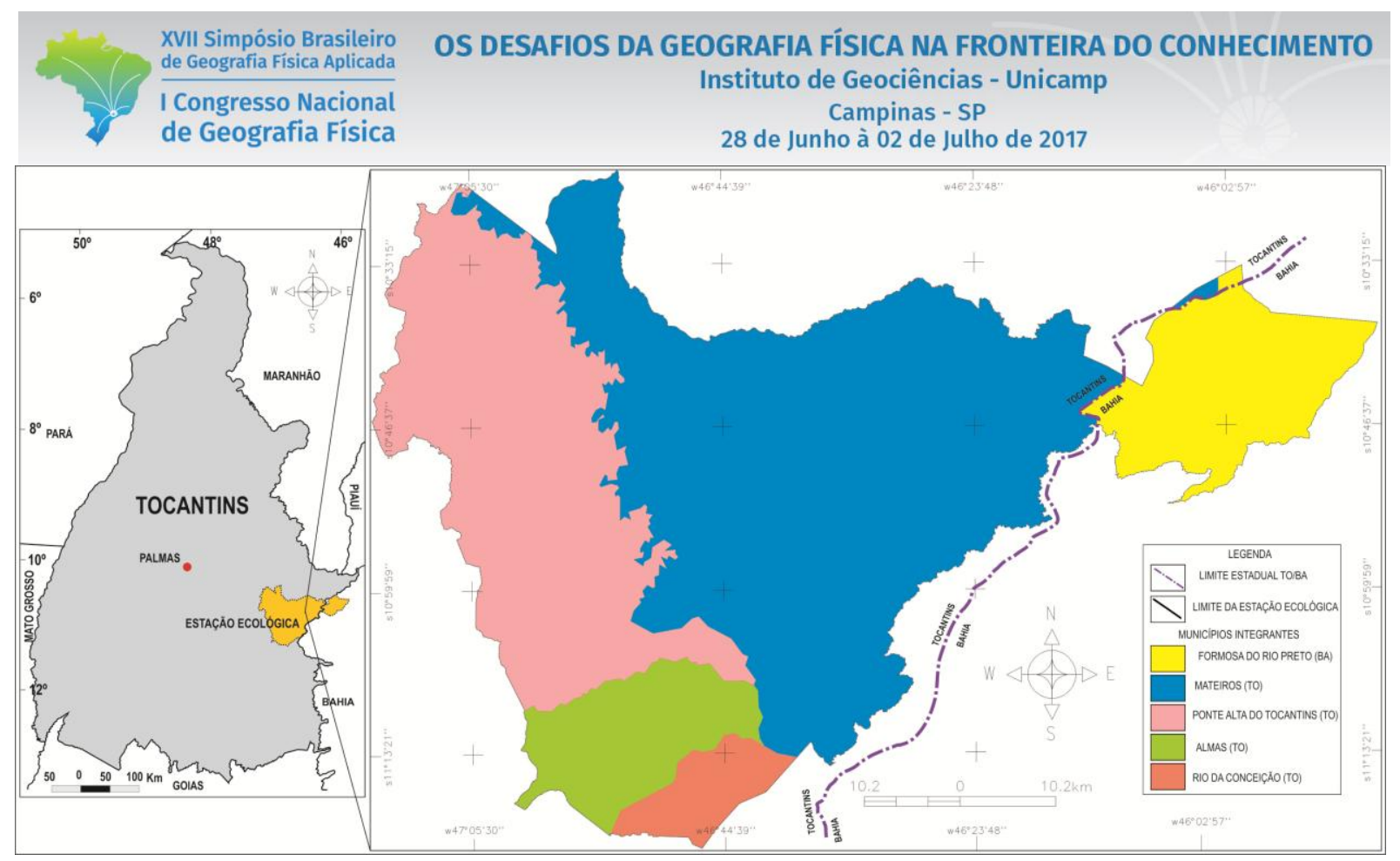

Figura 1. Localização da Estação Ecológica Serra Geral do Tocantins.

\section{Procedimentos Metodológicos}

No desenvolvimento do estudo foi realizado inicialmente um levantamento de materiais bibliográficos e cartográficos junto aos órgãos como: Secretaria de Planejamento e Meio Ambiente do Estado do Tocantins (SEPLAN) - Diretoria de Zoneamento Ecológico Econômico: arquivos digitais com dados do Estado do Tocantins e um mosaico de imagens do sensor TM do satélite LANDSAT 5, resolução espacial de 30m, de setembro de 2010, bandas espectrais 3, 4 e 5, órbitas ponto 221/67 - 221/68 - 220/67 - 220/68; Instituto Brasileiro de Geografia e Estatística (IBGE) e Diretoria do Serviço Geográfico do Ministério do Exército (DSG): as cartas topográficas na escala 1:100.000, datadas entre os anos de 1977 a 1981; Instituto Nacional de Pesquisas Espaciais (INPE): as imagens de radar Shuttle Radar Topography Mission (SRTM) TOPODATA (Valeriano e Albuquerque, 2010), cenas equivalente a carta na escala 1:250.000, índice 10/45, 10/48, 10/465, 11/45, 11/48, 11/464, 12/48, ambas com resolução espacial de 30 metros; Instituto Chico Mendes de Conservação da Biodiversidade (ICMBio): arquivos digitais para formação do banco de dados com informações básicas sobre a Estação Ecológica Serra Geral do Tocantins.

Os trabalhos de campo tiveram apoio do Instituto Chico Mendes de Conservação da Biodiversidade (ICMBio) e foram realizados percorrendo-se vários caminhos e estradas da região com uso de equipamentos como: GPS para localização geográfica e de máquina fotográfica digital para levantamento fotográfico dos aspectos fisiográficos e aferição das informações obtidas. 
Na definição das características morfométricas da rede de drenagem utilizou-se diversos parâmetros como: hierarquia fluvial, direção da rede de drenagem, magnitude total, comprimento total, densidade e padrões de drenagem. Estes parâmetros foram analisados conforme a descrição metodológica seguinte.

A hierarquia fluvial e a magnitude da rede de drenagem foi estabelecida seguindo-se a proposta de Strahler (1952) citado por Christofoletti, (1980). A Densidade de Drenagem (Horton (1945), citado Christofoletti (1974) foi calculado pela formula $\mathrm{Dd}=\mathrm{Lt} / \mathrm{A}$, em que: Dd - é a densidade de drenagem; Lt - o comprimento total dos canais e A - a área total da sub bacia hidrográfica. A definição dos padrões de drenagem foi realizada com base na metodologia de Strahler (1959) citado por Christofoletti (1974).

As formas e elementos do relevo foram definidos através de análise de imagens de satélite (Landsat) e radar (SRTM) apoiadas por diversos trabalhos de campo. Nestes também foram observadas a organização da drenagem; o substrato geológico; os aspectos pedológicos e os processos superficiais existentes na área de pesquisa.

\section{Caracterização Fisiográfica da Estação Ecológica Serra Geral do Tocantins}

O termo fisiografia provem do grego phisos (natureza) e graphos (descrição), significando assim, o processo de descrição da natureza. No meio científico, o termo fisiografia ainda carece de uma definição universalmente aceita, pois muitas vezes ela é utilizada como sinônimo de geomorfologia (THORNBURY, 1960) ou geografia física (DERRUAU, 1966).

Villota $(1992,2005)$ destaca que a fisiografia segue os mesmos princípios da geomorfologia em relação ao estudo das formas do relevo terrestre, entretanto, a principal diferença está nas respectivas classificações dessas geoformas.

Ainda, conforme o mesmo autor, enfatiza-se que a fisiografia tem por objetivo o estudo, caracterização e classificação das paisagens terrestres, levando em consideração seus fatores formadores e as relações que os afetam.

Os aspectos hidrográficos da área de estudo, estão relacionados com duas grandes bacias hidrográficas de importância nacional, as bacias dos Rios Tocantins-Araguaia e do São Francisco. Estas são constituídas por quatro bacias menores com grande influência no escoamento regional, que são: as bacias dos Rios Sono, das Balsas e Manoel Alves (integram a bacia do Rio Tocantins-Araguaia) e do Rio Preto (integra a bacia do Rio São Francisco). 
A maior hierarquia fluvial da área de pesquisa é de $6^{\circ}$ ordem, representada pelo Rio Novo, com uma rede de drenagem, apresentando uma direção predominante, na porção leste, SE-NW e, na porção oeste, NESW. Na sub-bacia deste rio, existe uma alta concentração de canais fluviais de $1^{a}$ ordem.

A densidade de drenagem total da área de pesquisa é de $0,43 \mathrm{~km} / \mathrm{Km}^{2}$, sendo que as sub-bacias hidrográficas que apresentam as maiores densidades de drenagens são: as do Córrego Grande $\left(0,73 \mathrm{~km} / \mathrm{Km}^{2}\right)$, do Rio Novo $\left(0,53 \mathrm{~km} / \mathrm{Km}^{2}\right)$ e do Rio Manoel Alves da Natividade $\left(0,53 \mathrm{~km} / \mathrm{Km}^{2}\right)$, sendo estas que possuem maior grau de dissecação topográfica pela atuação dos cursos fluviais.

Em síntese, os valores baixos de densidade de drenagem refletem a característica geral da área de estudo que está representada por um relevo predominantemente suave com condições de alta permeabilidade devido ao predomínio de litologias arenosas com um bom grau de infiltração de água no solo.

A sub-bacia hidrográfica do Rio Novo, Rio Vermelho, Rio do Santo e Córrego Grande apresentam padrão dendrítico-retangular, onde à rede de drenagem se distribui em várias direções, com a presença de anomalias pela existência de confluências em ângulos retos, junto as suas áreas de cabeceiras, demonstrando um controle estrutural da rede de drenagem.

A sub-bacia hidrográfica do Rio Sapão apresenta padrões treliça e retangular, sendo que o padrão treliça se caracteriza pelos canais de drenagem principais que correm paralelos recebendo afluentes que fluem em direções transversais a estes, formando ângulos retos e o padrão retangular, que se caracteriza pelas bruscas alterações retangulares nos cursos fluviais. Ambos os padrões de drenagem, demonstram um forte controle estrutural sobre a rede de drenagem da sub-bacia.

Já as sub-bacias hidrográfcas dos rios Ponte Alta, das Balsas e Manoel Alves da Natividade, apresentam um padrão paralelo onde os cursos fluviais sucessivos escoam quase que paralelamente uns aos outros. $\mathrm{Na}$ área, observa-se a predominância deste padrão, principalmente nas drenagens junto à escarpa de dissecação que formam uma faixa NW-SE.

As formas e elementos do relevo identificados permitem compartimentar a bacia em oito classes: Planície de Inundação, Dunas Eólicas, Vales Abertos, Vales Fechados, Colinas Arenosas, Morros e Morrotes, Mesas e Mesetas e a Chapada.

A Planície de Inundação abrange desde as áreas de depósitos de barras de pontal até as planícies de inundações, onde ocorrem significativas deposições sedimentares recentes. São oriundos de processos erosivos fluviais que ocorrem nas cabeceiras de drenagens proporcionando deposição nas áreas baixas, a jusante (Figura 2A). Corresponde a 2,9\% da área e se distribui em praticamente todos os setores da mesma, associadas aos vales abertos. 


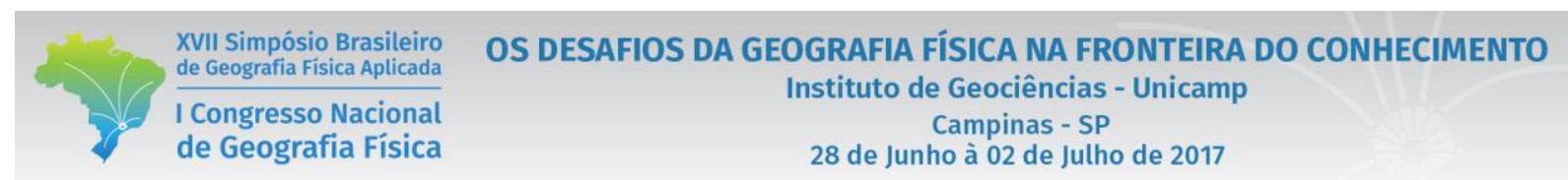

Na porção norte, na base da Serra do Espírito Santo, junto ao Riacho da Areia, os abundantes depósitos fluviais são retrabalhados pela ação do vento gerando uma feição muito característica que são as "Dunas do Jalapão". Essa feição ocorre em relevo suave ondulado com significativa deposição sedimentar recente ocasionado pela ação do vento. Sua origem está ligada ao retrabalhamento de depósitos arenosos, depositados por processos aquosos e pelo vento na base de encostas escarpadas (Figura 2B).
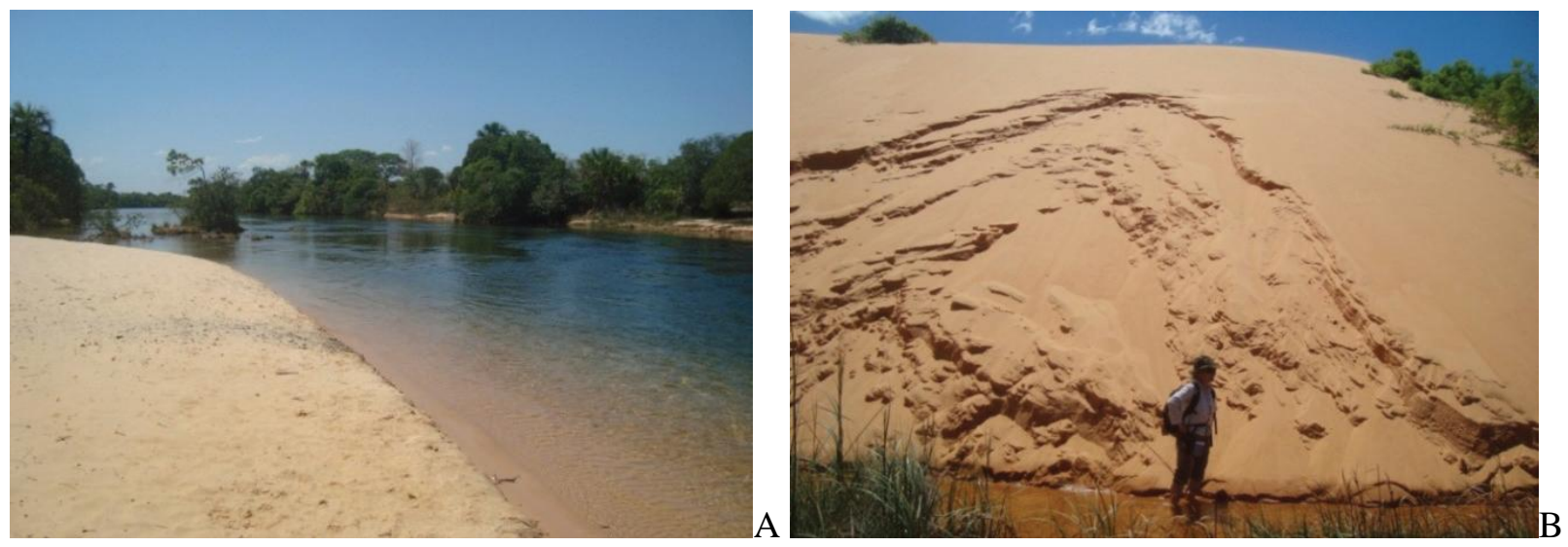

Figura 2. Depósitos em barra de pontal junto a drenagem (A) e as Dunas do Jalapão formada pelos sedimentos arenosos depositados e retrabalhadas pelo vento (B). Fotos: Autores, outubro de 2011.

Os Vales Abertos se caracterizam como relevos planos com menos de $2 \%$ de declividade onde ocorrem processos de deposição de sedimentos localizados junto às planícies de inundações dos cursos fluviais que compõem a rede de drenagem local (Figura 3A). É uma classe geomorfológica que compreende cerca de 19,4\% da área de pesquisa. Já os Vales Fechados são feições caracterizadas como canais encaixados que formam os cursos de água que compõem a rede de drenagem local (Figura 3B).
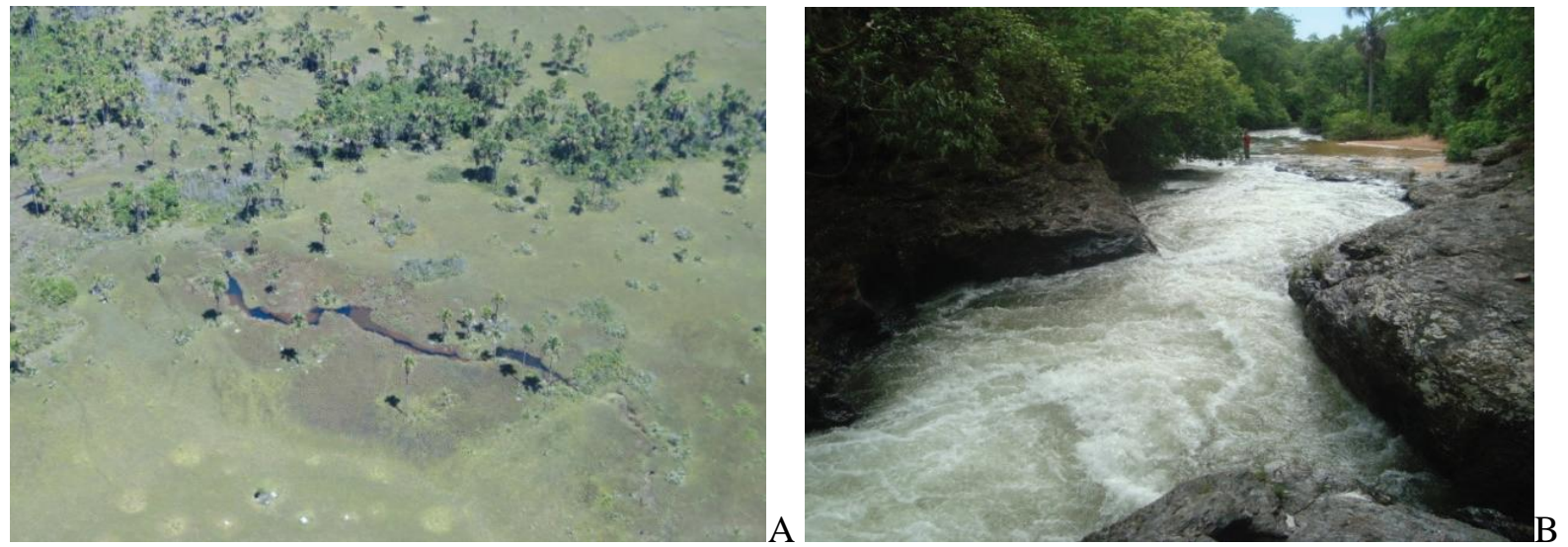

Figura 3. Vale Aberto em área de vereda (A) e Vale Fechado encaixado no embasamento rochoso junto ao Rio Manoel Alves (B). Foto (A): Côrtes, 2010 e Foto (B): Autores, outubro de 2010. 


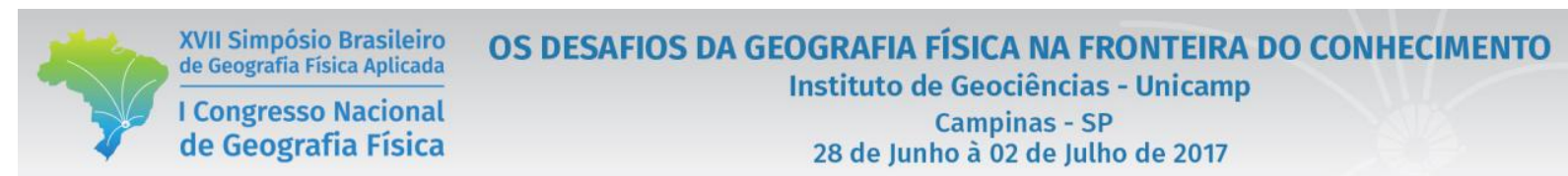

De maneira geral pode-se observar visualmente a beleza cênica e alguns aspectos físicos dos principais cursos fluviais que abrangem a Estação Ecológica Serra Geral do Tocantins (Figura 4)

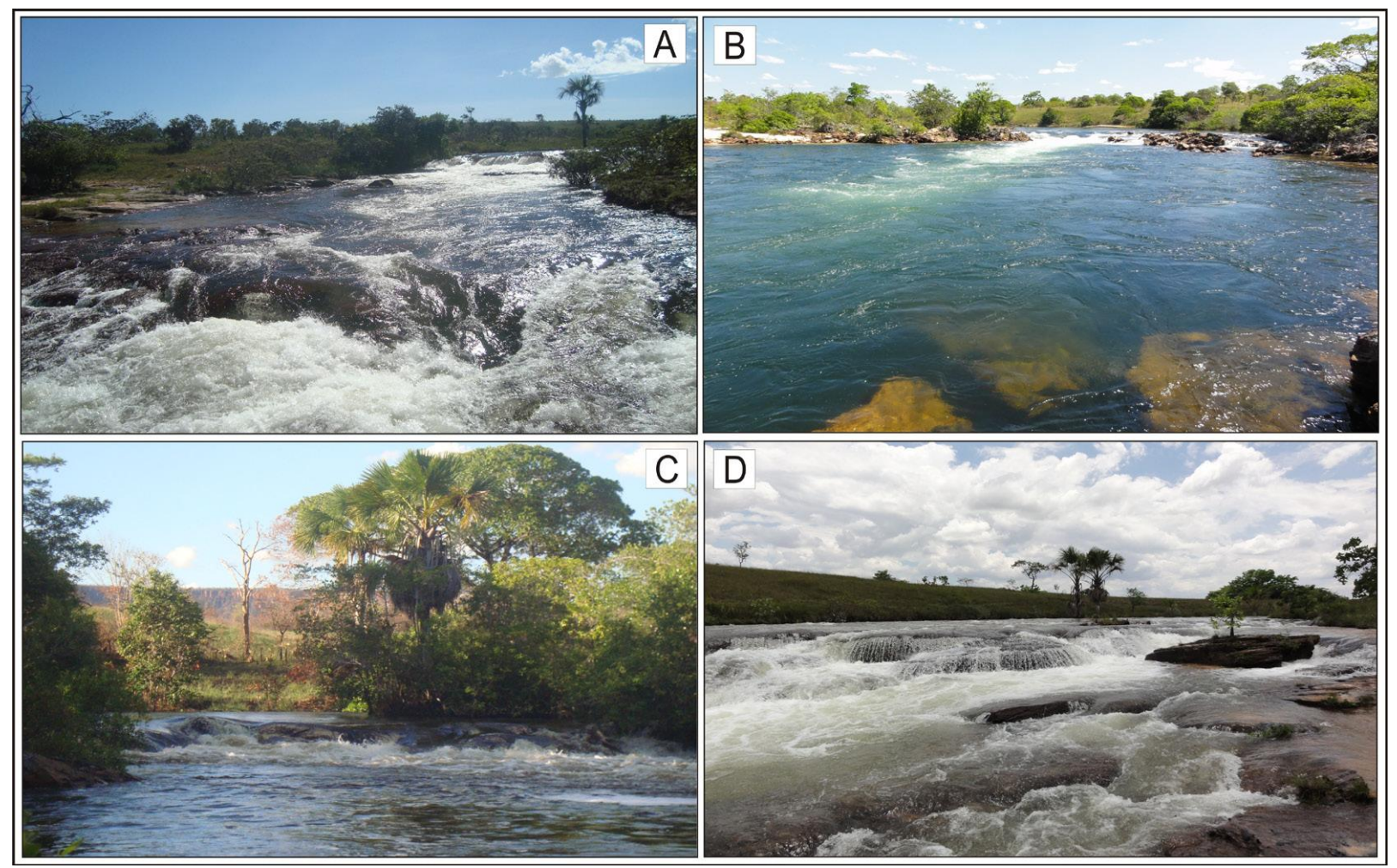

Figura 4. Características e beleza cênica dos principais cursos fluviais da Estação Ecológica Serra Geral do Tocantins: Rio das Balsas (A), Rio Novo (B), Rio Preto (C) e Rio Manoel Alves (D)

As Colinas Arenosas se caracterizam como um relevo levemente ondulado com declividade entre 5 e $15 \%$, em média $8 \%$, amplitudes entre 40 e $60 \mathrm{~m}$, substrato de arenitos e solos do tipo Neossolos Quartzarênicos (Figura 5A). Esta classe é predominante na área de pesquisa, correspondendo a cerca de $60 \%$, distribuindo-se por praticamente todos os setores.

Os Morros e Morrotes são relevos residuais com topo arredondado, com vertentes de inclinação superiores a $15 \%$ e, alguns com feições ruiniformes (Figura 5B). São feições que possuem um substrato arenítico resistente pela presença de cimentos ferruginosos com predominância de solos dos tipos Cambissolo e Neossolo litólico. Esta classe geomorfológica correspondendo a 0,4\% da área de pesquisa distribuindo-se em diversos setores com concentração na sua porção central, em especifico nas proximidades da linha de escarpa da Serra da Muriçoca. 


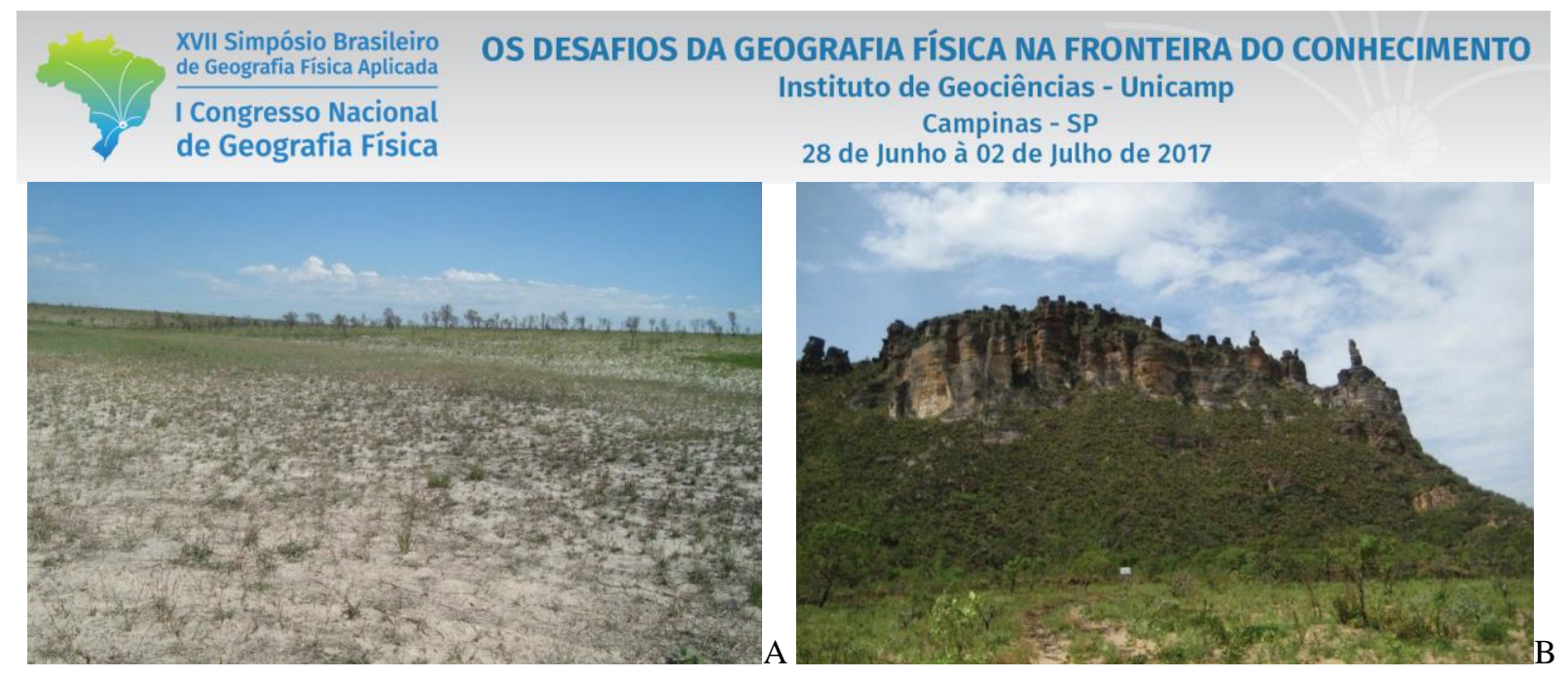

Figura 5. Colinas Arenosas com relevo suave ondulado (A) e Relevo Residual preservado presente na porção central da área de pesquisa (B). Foto (A): Autores, outubro de 2011 e Foto (B): Kabashima, outubro de 2011.

As Mesas e Mesetas formam feições típicas da área e são caracterizadas como relevos residuais tabulares descontínuos, formando elevações de topos planos com vertentes íngremes. Sendo que as Mesetas são determinadas por apresentarem amplitudes altimétricas menores que $100 \mathrm{~m}$, enquanto que, as Mesas apresentam amplitudes maiores que 100m (Figura 6A).

Estas feições são formadas por rochas sedimentares estratificadas, topos planos e encostas escarpadas, características de relevos tabulares que se apresentam no terreno como resquícios de rochas com maior coesão, dado por material cimentante preenchendo os poros, especialmente, sílica e óxido de ferro, o que permite a manutenção parcial de suas estruturas. Correspondem a 2,2\% da área, se distribuindo nos setores centro e norte da mesma.

As Chapadas se caracterizam por relevos tabulares, topos planos e retilíneos, com grande continuidade de área, originadas por recuo de escarpas. Possuem um substrato arenítico, relativamente, resistente pela presença de cimentos ferruginosos. Nessa classe ocorrem as maiores altitudes, da área de pesquisa, as quais apresentam na base das encostas escarpadas uma acumulação de material rochoso originado pela própria desagregação das Chapadas. Abrangem cerca de 14,7\% da área, distribuindo-se nos setores sudeste, leste e nordeste da mesma (Figura 6B). 


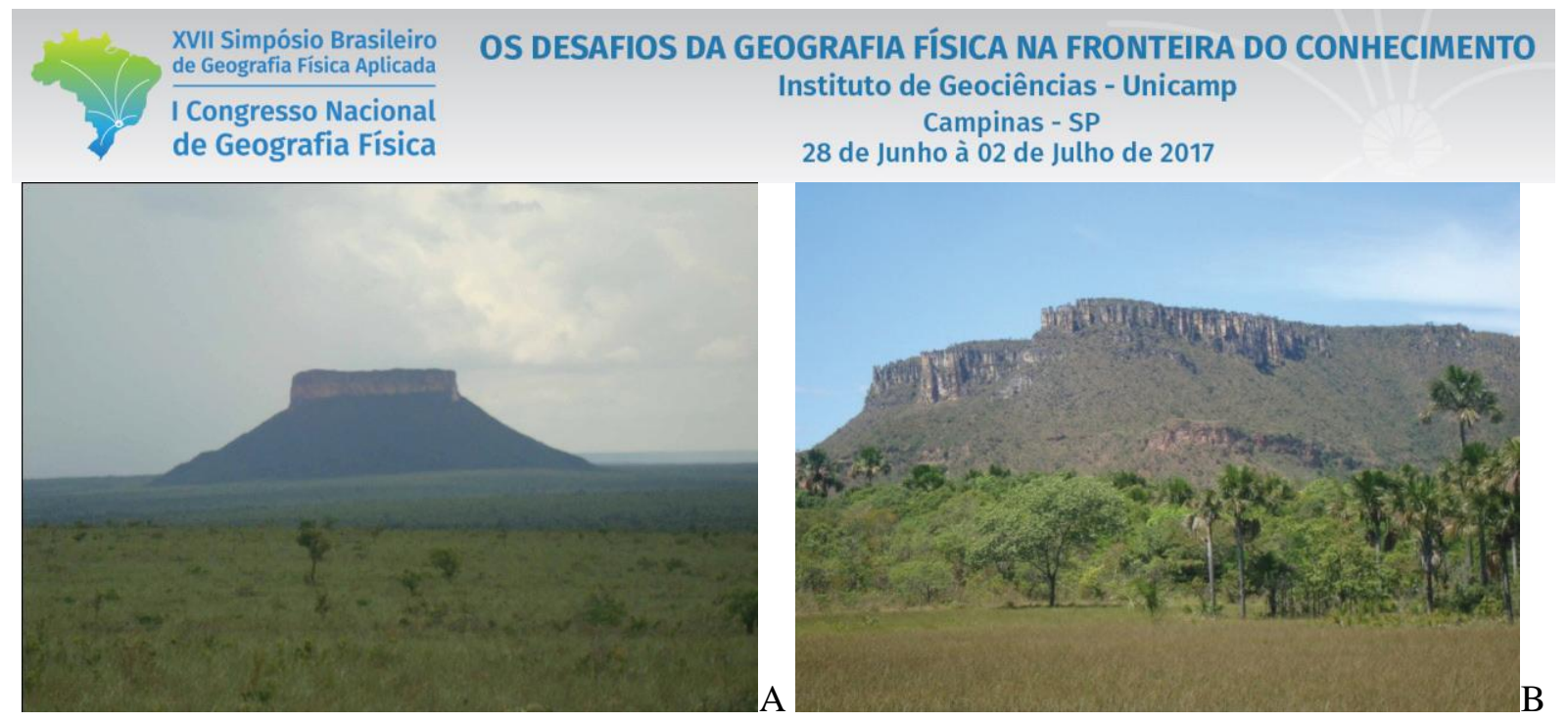

Figura 6. Feições de relevos com topos planos da área de estudo: Mesa como o Morro da Bigorna (A) e Chapada Ocidental da Bahia (B). Foto (A): C. Barreto, agosto de 2010 e Foto (B): Autores, agosto de 2011.

Ainda pode ser observada a Serra da Muriçoca, o principal patamar de dissecação que atravessa a área de pesquisa no sentido sudeste - noroeste (Figura 7A). Também, na base dos relevos tabulares, a existência de grandes depósitos de Talús e Colúvios formados por acúmulo de blocos e fragmentos de rochas, originados por intensos processos erosivos (Figura 7B).
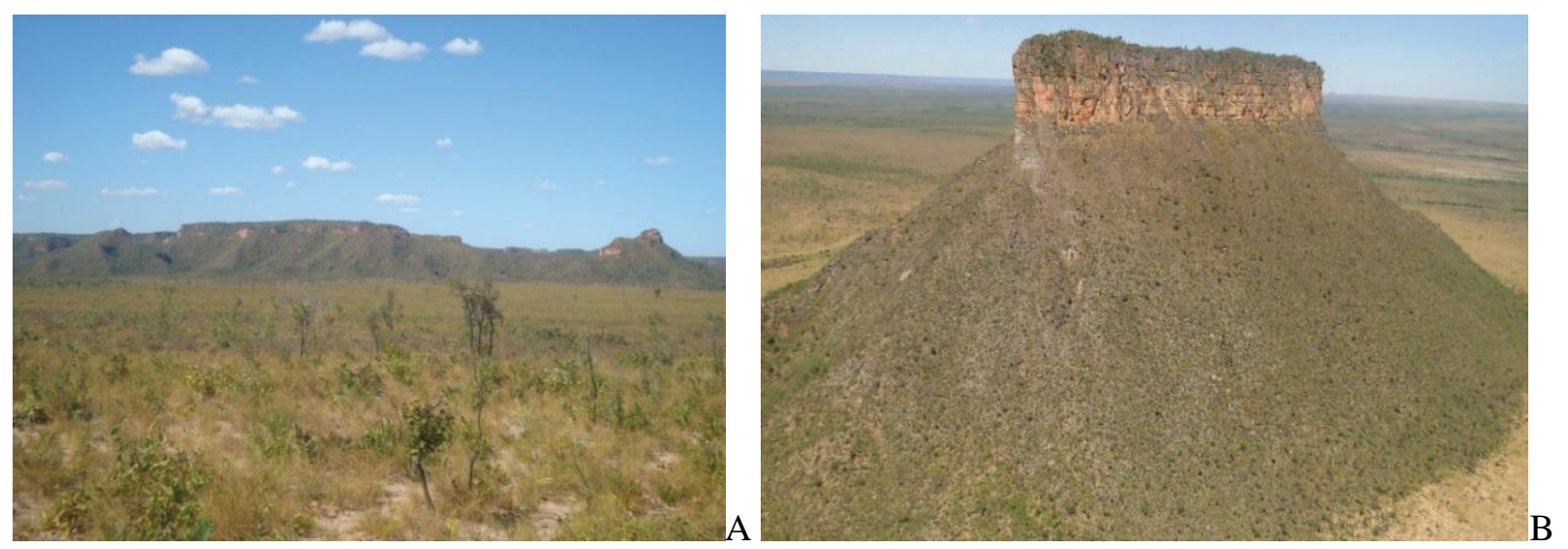

Figura 7. Escarpa na Serra da Muriçoca, porção noroeste da área (A) e Deposito de Talús e Colúvios, na base do morro da Bigorna, porção central da área (B). Foto (A): Autores, agosto de 2011 e Foto (B): Côrtes, 2010.

\section{Considerações Finais}

De modo geral, com a presente análise fisiográfica pode-se verificar que tanto a hidrografia quanto a geomorfologia, são fatores elementares na caracterização ambiental da área de pesquisa e servem de instrumentos de planejamento e gestão ambiental. Esta análise também é importante porque permite a 
integração das relações que se estabelecem entre a rede de drenagem e o relevo com os processos que compõem e transformam a paisagem local.

Nos aspectos morfométricos destacam-se a maior hierarquia fluvial é de $6^{\circ}$ ordem, representada pelo Rio Novo; a direção da rede de drenagem predominante representada, na porção leste, por uma direção dos canais de SE a NO e na porção oeste por uma direção dos canais de NE para SO; a magnitude total é de 1.473 canais de escoamento de $1^{\mathrm{a}}$ ordem; a densidade de drenagem total é de $0,43 \mathrm{~km} / \mathrm{Km}^{2}$, sendo que a sub-bacia que apresenta maior densidade é a do Córrego Grande $(0,73 \mathrm{~km} / \mathrm{Km})$; o padrão de drenagem predominante é o retangular, indicando de modo geral um forte controle estrutural da geologia local sobre a rede de drenagem.

Destaca-se a diversidade de formas e processos que compõem a paisagem e que possuem uma relação direta com a manutenção da fauna e a da flora local. Entre estas estão as planícies de inundações, onde ocorrem significativas deposições sedimentares recentes; a dunas eólicas, depósitos recentes pela ação do vento; os vales abertos, associados a curso d'água em áreas planas com menos de $2 \%$ de declividade; os vales fechados, quando a rede de drenagem encontra-se sob controle estrutural de lineamentos geológicos; as colinas arenosas, com relevo levemente ondulado em substrato de arenitos e solos arenosos; morros e morrotes, representadas por relevos residuais com topos arredondados; mesas e mesetas, caracterizadas como relevos residuais tabulares descontínuos e; chapadas, que são relevos tabulares, topos planos e retilíneos, com grande continuidade de área.

Em síntese, a análise fisiográfica permitiu verificar que a hidrografia e a geomorfologia, são elementos fundamentais para a Estação Ecológica da Serra Geral do Tocantins, servido como elementos chaves na conservação ambiental do Cerrado e da vida local como um todo, tanto dos animais, como dos vegetais e principalmente dos seres humanos que fazem uso direto e indireto da área.

\section{Bibliografia}

Brasil. Decreto Lei $\mathbf{s} / \mathbf{n}^{\mathbf{0}}$ de 27 de setembro de 2001. Disponível em: http://www.planalto.gov.br/ccivil_03/dnn/2001/Dnn9337.htm Acesso em 24 de fevereiro de 2011

BRASIL. Lei $\mathbf{n}^{\mathbf{0}}$ 9.985. Brasília: 18 de julho de 2000. Disponível em: <http://www. planalto.gov.br/ccivil_03/Leis/L9985.htm>. Acesso em: 24 fev. 2011

CHRISTOFOLETTI, A. Geomorfologia Fluvial. São Paulo - SP: Edgard Blücher, 1980.

CHRISTOFOLETTI, A. Geomorfologia. São Paulo: Edgard Blücher, Ed. Da Universidade de São Paulo, 1974. $150 \mathrm{p}$

DERRUAU, M. Geomorfologia. Trad. Luis Sole Sabaris, Barcelona, Ediciones Ariel, 1966, 442p. 
GUERRA, A. J. T. e MARÇAL, M. S. 2006. Geomorfologia Aplicada ao Turismo. In: Geomorfologia Ambiental. Rio de Janeiro: Bertrand Brasil, p. 42-46.

MILANI, J. R. e CANALI, N. E. O Sistema Hidrográfico do Rio Matinhos: uma análise morfométrica. Curitiba PR: R. RA'EGA, Editora da UFPR, n. 4, 2000.Disponível em: file://C:/Users/SandroSidnei/Downloads/3345-65341-PB.pdf. Acesso em fevereiro de 2011

MYERS, N. R. A. et al,. Biodiversity hotspots for conservation priorities. Nature, 403, 2000.

SEPLAN. Atlas do Tocantins: Subsídios ao Planejamento da Gestão Territorial. Palmas - TO: Secretaria do Planejamento e da Modernização Pública - SEPLAN, Superintendência de Pesquisa e Zoneamento EcológicoEconômico, Diretoria de Zoneamento Ecológico-Econômico - DZE, 6 ed. 2012. 80 pag.

THONRBURY, W.D. Princípios de Geomorfologia. Buenos Aires: Ed. Kapelusz,1960.

VAleriano, M. de M. e AlBUQUERQUE, P. C. G. de. TOPODATA: Processamento dos dados SRTM. São José dos Campos - SP: INPE, 2010. Disponível em: http://www.dsr.inpe.br/topodata/documentos.php. Acesso em janeiro de 2010.

VILLOTA H. Geomorfología aplicada a levantamientos edafológicos y zonificación física de tierras. Bogotá: Instituto Geográfico Agustín Codazzi, 2005.

VILLOTA, H. El sistema CIAF de classificacion fisiografica del terreno. Bogotá: Revista CIAF, v.13, n.1, pp. 55$70,1992$. 